\title{
Assessment of Knowledge, Attitude and Practice of Contraceptive Use among Postpartum Women in Jimma University Medical Center, Jimma Town, South West Ethiopia
}

\author{
Tilahun Wodaynew ${ }^{1^{*}}$ and Dinkinesh Bekele ${ }^{2}$ \\ ${ }^{1}$ School of Nursing and Midwifery, Collage of Health Science, Institute of Health, Jimma University, Ethiopia \\ 2Jimma University Medical Centers, Jimma University, Ethiopia
}

*Corresponding author: Tilahun Wodaynew, School of Nursing and Midwifery, Collage of Health Science, Institute of Health, Jimma University, Ethiopia

\begin{abstract}
Background: Population growth remains high in the group of 48 countries designated by the United Nations as the least developed countries (LDCs), of which 27 are in Africa. Ethiopia, the second most populous country in Africa, still has high fertility rate (4.6 children per woman) and fast population growth rate. Despite the enormous benefits of using modern contraceptive methods, the utilization of contraceptives remains low in Sub-Saharan Africa including Ethiopia. Many women in the postpartum period do not start to use contraception until the return of menstruation.
\end{abstract}

Objective: To assess knowledge, attitude and practice of contraceptive use among postpartum women in JUMC, southwest Ethiopia, 2019.

Methods: Facility based cross-sectional was conducted among postpartum women who admitted to postnatal ward of JUMC during the study period. The Study was conducted by using Systematic random sampling technique. Data was collected through face to face interview from December 1 to 30,2019 . Data collection tool was developed by reviewing related literatures. Data was coded and analyzed using manual compilation of the questionnaires. Descriptive statistics was used to describe the variables and the study result was presented in tables, chart and statements.

Result: Only 98 (92.5\%) of the respondents had heard about family planning. About $65.7 \%$ of respondents have good knowledge, 34.3\% have poor knowledge. Out of 106 respondents $74(69.8 \%)$ have positive attitude towards contractive and the remaining $32(30.2 \%)$ had negative attitude. Out of 106 respondents $62(58.5 \%)$ of respondents had a safe practice and the remaining $44(41.5 \%)$ were unsafe practice towards contraceptive use.
Conclusion: Nearly two third of respondents were knowledgeable. More than two third of respondents were positive attitude towards contractive. More than four fifth were interest to know about family planning. About more than half of respondents had a safe practice and about four fifth of respondents were used contraceptive to prevent unwanted pregnancy.

\section{Keywords}

Knowledge, Attitude, Practice, Contraceptive use, Jimma university medical center

\begin{abstract}
Abbreviations
EDHS: Ethiopian Demographic Health Survey; FP: Family Planning; HIVIAIDS: Human Immune virus/Acquired Immune Deficiency Syndrome; IUCD: Intra Uterine Contraceptive Device; JIPMER: Jawaharlal Institute of Postgraduate Medical Education and Research; JUMC: Jimma University Medical Center; MT Pill: Medical Termination of Pregnancy Pill; OCP: Oral Contraceptive Pill; PPFP: Postpartum Family Planning; TFR: Total Fertility Rate; UNFPA: United Nation Population Fund; USAID: United States Agency for International Development; WHO: World Health Organization
\end{abstract}

\section{Introduction}

In 2015, world's population reached 7.3 billion. Population growth remains high in the group of 48 countries designated by the United Nations as the least developed countries (LDCs), of which 27 are in Africa [1]. 
Using modern Contraceptive method is widely approved as an important intervention towards achieving national and international goals, as it has proven to reduce maternal and child mortality and morbidity [2].

Maternal health problems remain a major global concern since pregnancy and childbirth are the leading causes of morbidity and mortality among reproductive age women [3]. Evidences have shown that encouraging early antenatal care visits, institutional deliveries, postnatal care, and contraceptive adoption are the key elements in improving safe motherhood. As the first pillar of safe motherhood and an essential component of primary health care, contraceptive plays a key role in reducing maternal and newborn morbidity and mortality by preventing unintended pregnancy and close birth intervals [4].

A closed birth interval would endanger the lives of the mother, the newborn, and the (previously delivered child). When a mother becomes pregnant shortly after childbirth, she is more likely to develop complications including spontaneous abortion, postpartum bleeding, and anemia. Secondly, the newborn could be born low birth weight and/or preterm. Thirdly, the index child (previously delivered child) might receive inadequate care and support which, thereafter, could lead to vulnerabilities to disease and malnutrition $[4,5]$.

The majority of women resume sexual activity within several weeks of the delivery. The amount of time following delivery that a woman is infertile is highly variable and dependent on multiple factors, including breastfeeding status. Ovulation can occur even if the mother has not resumed menstruation and could happen as early as 25 days postpartum. The probability of ovulation occurring before resumption of menstruation increases over time [6]. Postpartum family planning (PPFP) focuses on the prevention of unintended and closely spaced pregnancies through the first 12 months following childbirth [7]. Unmet needs could lead to unplanned and unintentional pregnancies which will increase the risk of adverse maternal and neonatal health outcomes [8].

In order to reduce the risk of adverse maternal, prenatal and infant outcomes, WHO, recommended that the interval between a live birth and an attempt to the next pregnancy should be 24 months $[9,10]$. Short birth intervals (< 24 months) also have a potential effect on the Contraceptives are used by the majority of married or in-union women in almost all regions of the world. Within these major areas there are large differences by region. Prevalence in 2015 was several times as high in Northern Africa and Southern Africa (53 per cent and 64 per cent, respectively) as in Middle Africa (23 per cent) and Western Africa (17 per cent). Contraceptive use has been increasing recently in Eastern Africa and now stands at 40 per cent [11].

The most recent Ghana Demographic and Health
Survey showed a CPR in 2014 of 26.7\% [12]. In Ethiopia in-depth analysis of the EDHS 2000-2011 shows that a contraceptive use has seen a dramatic increase in contraceptive prevalence rate (CPR) over the last decade from a low of $8.2 \%$ in 2000 to $14.7 \%$ in 2005 and $28.6 \%$ in 2011 [13]. Nowadays, $41 \%$ of currently married women are using any modern contraceptive methods in EDHS 2019 [14].

Knowledge of family planning is considered the first stage toward the adoption of a contraceptive method. Lack of adequate knowledge and awareness has been found to be associated with lack of contraceptive use among young women. Its use has been found to be associated with having previously been pregnant, meaning it is only after a pregnancy that young women are educated about and subsequently offered contraceptives services [15]. Lack of awareness and poor knowledge of contraceptives methods has been found to be common among young women seeking for abortion [16]. Many who report familiarity with contraceptive were found to be having misinformation and very few knew the correct timing of use. Lack of detail and accurate information on contraceptive was found to have resulted in reluctance to adopt family planning method as some will want to know its side effect and contra indications [17].

The study conducted in India tertiary care center shows that Among the 230 women enrolled only 69\% had heard about various methods of contraception. Only $65.95 \%$ women after one delivery or abortion had heard about contraception compared to $71.3 \%$ after two or more deliveries [18].

Study done aimed to determine the knowledge, attitude and practice of contraception among the postpartum women attending Kathmandu Medical College Teaching Hospital majority of the participants $363(90.8 \%)$ were aware of contraceptive usage [19].

Study done undertaken to explore the knowledge level, attitude and the factors influencing the potential use of spacing contraception among recently delivered women JIPMER, Puducherry- (a tertiary care Centre), India Among the 404 women studied, The level of awareness about contraception was $70 \%$ though only $30 \%$ knew the correct use [20]. Study undertaken to evaluate the knowledge and attitude about contraception in postpartum women in a tertiary care medical college in North India. Among Five hundred (500) postpartum and post-abortal women were randomly selected in their study observed that only $72 \%$ of the ladies had heard about various methods of contraception [21].

Study was conducted to assess postpartum modern contraceptive use and associated factors among women in the extended postpartum period in the town of Aksum, northern Ethiopia. Nearly half (48.0\%) of the women reported using modern contraceptive methods 
during the extended postpartum period [22].

According to Ethiopian Demographic Health Survey 2019 shows that Overall, $41 \%$ of currently married women are using modern contraceptive methods, and $1 \%$ are using traditional methods. The most used popular contraceptive methods are also increased from EDHS 2016 to 2019 as follows injectable (23\% to 27\%), followed by implants ( $8 \%$ to $9 \%$ ), and regarding to the pill and the IUD there is no increment it's the same as previous which is ( $2 \%$ in each). This shows the modern contraceptive methods usage increased dramatically from 35\% in EDHS 2016 to 41\%. This can be translated to an average of $2 \%$ increase per annum [14,23].

A study conducted in Adama shows that the overall knowledge $63.6 \%$ and $36.4 \%$ participants have good and poor knowledge about contraceptive, respectively. Accordingly more than half of $(56.4 \%)$ of the respondents have positive attitude and support use of contraceptives and $43.6 \%$ of them ad negative attitude for contraceptive use [24]. Another study conducted in Kebribeyah Town, Somali Region shows that among the respondents of 343,234 (68.2\%) had good knowledge. Whereas, one hundred nine (31.8\%) of the respondents had poor knowledge on postpartum contraceptive. Among the respondents, 278 (51\%) had favorable attitude toward postpartum contraceptive [25].

A study conducted in northwest Ethiopia shows that Three fourth (75.3\%) of study participants ever used contraceptive methods. Almost half (50.4\%) of study participants had good practice and the rest $49.6 \%$ had poor practice [26].

However, the study conducted in Uttar Pradesh India Shows those $71.22 \%$ and $51.71 \%$ respondents that had knowledge and safe contraception practice [27]. Another study conducted in Pakistan shows that of 100 interviewed women, $53(53 \%)$ had safe practice regarding to contraceptive methods [14]. Similarly a study conducted in Mahasamund district in Chhattisgarh State, India shows that there is a marked gap existing between knowledge and practice of family planning methods. About 78 (48.44\%) members had safe practice towards contraceptive use while 83 (51.55\%) members had unsafe practiced [28]. Therefore the aims of this study is to assess knowledge, attitude and practice of contraceptive use among postpartum women in JUMC, Jimma town, south west Ethiopia.

\section{General Objective}

$>$ To assess knowledge, attitude and practice of contraceptive use among postpartum women in JUMC, Southwest Ethiopia, 2019.

\section{Specific Objective}

> To determine knowledge of contraceptive use among postpartum women in JUMC, 2019.

> To assess attitude of contraceptive use among postpartum women in JUMC, 2019.

To describe practice of contraceptive use among postpartum women in JUMC, 2019.

\section{Methods and Materials}

\section{Study area and period}

The study was conducted in JUMC, Jimma town. The reproductive age groups are $64,200(21 \%)$ and provided with the health services including two Hospitals, three health centers and with some private health institution. JUMC is one of the oldest public hospitals in the country. It was established in 1930 E.C. Geographically it is located in Jimma city $352 \mathrm{~km}$ southwest of the capital Addis Ababa and above sea level $1780 \mathrm{~m}$ and it has latitude and longitude of $7^{\circ} 40^{\prime} \mathrm{N} 36^{\circ} 50^{\prime} \mathrm{E}$. Previously, it has been governed under Ethiopian government by the name of "Ras Desta Damtew Hospital" and later "Jimma Hospital" during dergue regime and currently named as Jimma university medical center. Currently, the hospital with 800 beds is expected to provide health services for more than 20 million peoples living in south western of Ethiopia and also give services for south Sudan and neighboring countries. Besides of this, the hospital will serve as teaching, health and research center.

This study was conducted in JUMC at postnatal ward mothers which admitted during study period from December 1 to 30, 2019.

\section{Study design}

Facility based cross-sectional was conducted among postpartum women who admitted to postnatal ward of JUMC during the study period.

\section{Source of population}

The source of population was all postpartum mothers in JUMC.

\section{Study population}

All sampled postpartum mothers who were admitted to postnatal ward of JUMC during study period.

\section{Inclusion and exclusion criteria}

Inclusion criteria: All mothers who were attending postnatal care at JUMC during the study period and volunteer to participate in the study.

Exclusion criteria: Critical ill mothers, unable to communicate mothers were excluded from the study.

\section{Sample size determination}

The sample size was determined by using the formula of estimate of single population proportion.

$$
n=\frac{\left(Z \frac{\alpha}{2}\right)^{2} P(1-P)}{d^{2}}
$$


Where, $Z \frac{\alpha}{2}=1.96$ confidence interval $95 \%$ and $5 \%$ margin of error $(d=0.05)$

The proportion will be $48 \%$ from previous study conducted in Axum northern Ethiopia ( $p=0.48$ ).

$$
n=\frac{(1.96)^{2} 0.48(1-0.48)}{(0.05)^{2}}=383.54 \approx 384
$$

Since, the source of population relatively small (less than 10,000 ) we should adjust the sample size by using correction formula as follows.

The total number of women who attend post-natal ward $(\mathrm{N})$ will be estimated by considering the immediate previous three month records of post-natal ward (378/3 $=126$ ) and the final sample size was

$$
n=\frac{n_{0}}{\left(1+\frac{n_{0}}{N}\right)} n=\frac{384}{1+\frac{384}{126}}=96
$$

Where, $\mathrm{n}=$ New sample size $=96$

$\mathrm{n}_{0}=$ Initial sample size $=384$

$\mathrm{N}=$ Total population $=126$

By adding $10 \%$ non-response rate, the sample size was 106.

\section{Sampling procedures}

The Study was conducted by using Systematic random sampling technique. The first participant was chosen by lottery method and all the next participant was selected based on interval $(k)$. By taking the flow of post-natal ward attendants of JUMC from JUMC postnatal registration book in month August, September and October 2019, there is 160,113 and 105 postnatal followers at JUMC, respectively, and by taking the average $(160+113+105 / 3=378 / 3=126$ which is $\mathrm{N})$. Then, $\mathrm{k}=126 / 106=1.188^{\sim} 1$. Assuming this flow of attendants will occur in our study period the data was collected until total sample size achieved.

\section{Study variables}

Dependent variables: Knowledge, attitude and practice of postpartum mothers.

\section{Independent variables}

Sociodemographic factors: Age, parity, urban, rural, educational status, religious, marital status, husband education.

Maternal factors: Number of pregnancy, number of alive children, sex of children.

\section{Operational definitions and terms}

Knowledge: Knowledge was defined as being aware of and mentioning at least two contraceptive methods. mother who responds correctly for at least three or more postpartum contraceptive method question is considered having good Knowledge.

Poor knowledge: According to this study the mother who responds correctly for one or less postpartum contraceptive method question is considered having poor knowledge.

Favorable (positive) attitude: Those who are able to answer $\geq 70 \%$ of the attitude questions correctly will be regarded as having favorable attitude.

Unfavorable (negative) attitude: Those who are able to answer $<70 \%$ of attitude questions will be regarded as having unfavorable attitude.

Safe practice: If the client answers greater than or equal to $70 \%$ postpartum contraceptive method practice questions correctly she would be considered having good practices.

Unsafe practice: If the client answers less than $70 \%$ about postpartum contraceptive method practice questions she would be considered as having poor practice.

\section{Data Collection Technique and Tools}

A semi-structured questionnaire was adapted by reviewing different literature, prepared by English version translated to Afan Oromo and prepared to assess knowledge, attitude and practice of contraceptive use among postpartum mothers in JUMC. The data was collected by two trained staffs through face to face interview of the delivered mothers and the data collection was strictly supervised by two bachelor health professionals. The questionnaires contain sociodemographic characteristics and knowledge, attitude \& practice level of mothers in the study period towards contraceptive use. Daily meeting was conducted between data collectors, supervisors and principal investigator for discussion regarding presenting difficulties and to assess the progress of data collection.

\section{Quality control}

To ensure the consistence of data collection tool the questionnaire was prepared in English and translated in Afan Oromo language \& re-translated back to English to make the consistency of the instrument. To maintain the quality of data pre-test was done on $5 \%$ of the sample at shenon gibe hospital to knew whether the questions are clearly understandable or not before moving to the study and data collectors was trained before actual data collection. The questionnaires and collected data was checked daily for completeness, consistency, sensitivity and how much it address the objective of the study and then measurement was taken to correct the questionnaire accordingly before data processing and analysis.

Good Knowledge: According to this study the 


\section{Data processing and analysis}

Data was checked for its completeness and correctness. Data was coded and analyzed using manual compilation of the questionnaires. To explain the study population in relation to relevant variables, descriptive statistics such as, frequencies, and percentages was calculated. Result was presented in tables and charts.

\section{Ethical consideration}

Ethical clearance letter was obtained from Jimma University institutional review board (IRB). Further, for each study participant the objective of the study was stated by data collectors. In addition the purpose of data collection was explained first to respondents to increase their awareness about the study before the start of the interview. Confidentiality of the information was assured and privacy of the study population was respected and kept as well.

\section{Dissemination plan}

The result of the study was submitted to Jimma University, institute of health, Faculty of health sciences, school of nursing and midwifery as a requirement for partial fulfillment of BSc degree in Midwifery. The findings will be presented in different seminars, meetings and workshops and may also be made publically accessible through publications in international reputable journals.

\section{Result}

\section{Sociodemographic characteristics of respondents}

A total of 106 postpartum women were participated in the study with a respondent rate $100 \%$. Sociodemographic characteristics of the respondents as indicated in Table 1 below showed that $44(41.5 \%)$ were urban and 72 (68\%) were between 25 and 34-yearsold. The educational level of mothers showed that 32

Table 1: Socio-demographic characteristic of postpartum women who attend postnatal ward at JUMC, from December 1 to 30 , 2019.

\begin{tabular}{|c|c|c|c|}
\hline Variables & Categories & Frequency & Percentage \\
\hline \multirow[t]{2}{*}{ 1. Address } & Urban & 44 & 41.5 \\
\hline & Rural & 62 & 58.5 \\
\hline \multirow[t]{3}{*}{ 2. Age } & $15-24$ & 23 & 21.6 \\
\hline & $25-34$ & 72 & 68 \\
\hline & $35-45$ & 11 & 10.4 \\
\hline \multirow[t]{5}{*}{ 3. Educational status } & Not read and write & 32 & 30.1 \\
\hline & Elementary $1^{\text {st }}$ cycle (1-4 grade) & 19 & 18 \\
\hline & Elementary $2^{\text {nd }}$ cycle (5-8 grade) & 26 & 24.5 \\
\hline & $\begin{array}{l}\text { High school and preparatory school } \\
\text { (9-12 grade) }\end{array}$ & 18 & 17 \\
\hline & College \& University & 11 & 10.4 \\
\hline \multirow[t]{2}{*}{ 4. Marital status } & Married & 92 & 86.8 \\
\hline & Unmarried & 14 & 13.2 \\
\hline \multirow[t]{4}{*}{ 5. Religious } & Orthodox & 33 & 31.1 \\
\hline & Muslim & 48 & 45.3 \\
\hline & Protestant & 19 & 18 \\
\hline & Others $^{*}$ & 6 & 5.6 \\
\hline \multirow[t]{4}{*}{ 6.Occupational status } & Housewives & 58 & 54.7 \\
\hline & Government employee & 22 & 20.8 \\
\hline & Merchants & 18 & 17 \\
\hline & Others ${ }^{* *}$ & 8 & 7.5 \\
\hline \multirow[t]{5}{*}{ 7. Monthly income in birr } & $<=1000$ & 12 & 11.3 \\
\hline & $1001-1500$ & 14 & 13.2 \\
\hline & $1501-2000$ & 19 & 18 \\
\hline & $2001-2500$ & 21 & 19.8 \\
\hline & $>=2500$ & 40 & 37.7 \\
\hline \multirow[t]{4}{*}{ 8. Number of pregnancy } & One & 12 & 11.3 \\
\hline & Two & 20 & 19 \\
\hline & Three & 25 & 23.5 \\
\hline & Four and above & 49 & 46.2 \\
\hline
\end{tabular}




\begin{tabular}{|l|l|l|l|}
\hline 9. Distance from health facilities & $=<5 \mathrm{~km}$ & 10 & 9.4 \\
\cline { 2 - 3 } & $5.1-10 \mathrm{~km}$ & 16 & 15.1 \\
\hline \multirow{5}{*}{ 10. Number of alive children } & $>10 \mathrm{~km}$ & 80 & 75.5 \\
\hline \multirow{5}{*}{ 11. Number of abortion } & None & 18 & 17 \\
\cline { 2 - 4 } & One & 8 & 7.5 \\
\hline & Two & 10 & 9.4 \\
\hline & Three & 12 & 11.3 \\
\hline & Four and above & 58 & 54.7 \\
\hline & None & 89 & 84 \\
\hline & One & 11 & 10.4 \\
\hline & Two & 6 & 5.6 \\
\hline & Three & 0 & 0 \\
\hline & Four and above & 0 & 0 \\
\hline
\end{tabular}

*: Catholic, wakefeta; ${ }^{* *}$ : Private employee, student, daily workers.

\section{The Source of information for family planning}

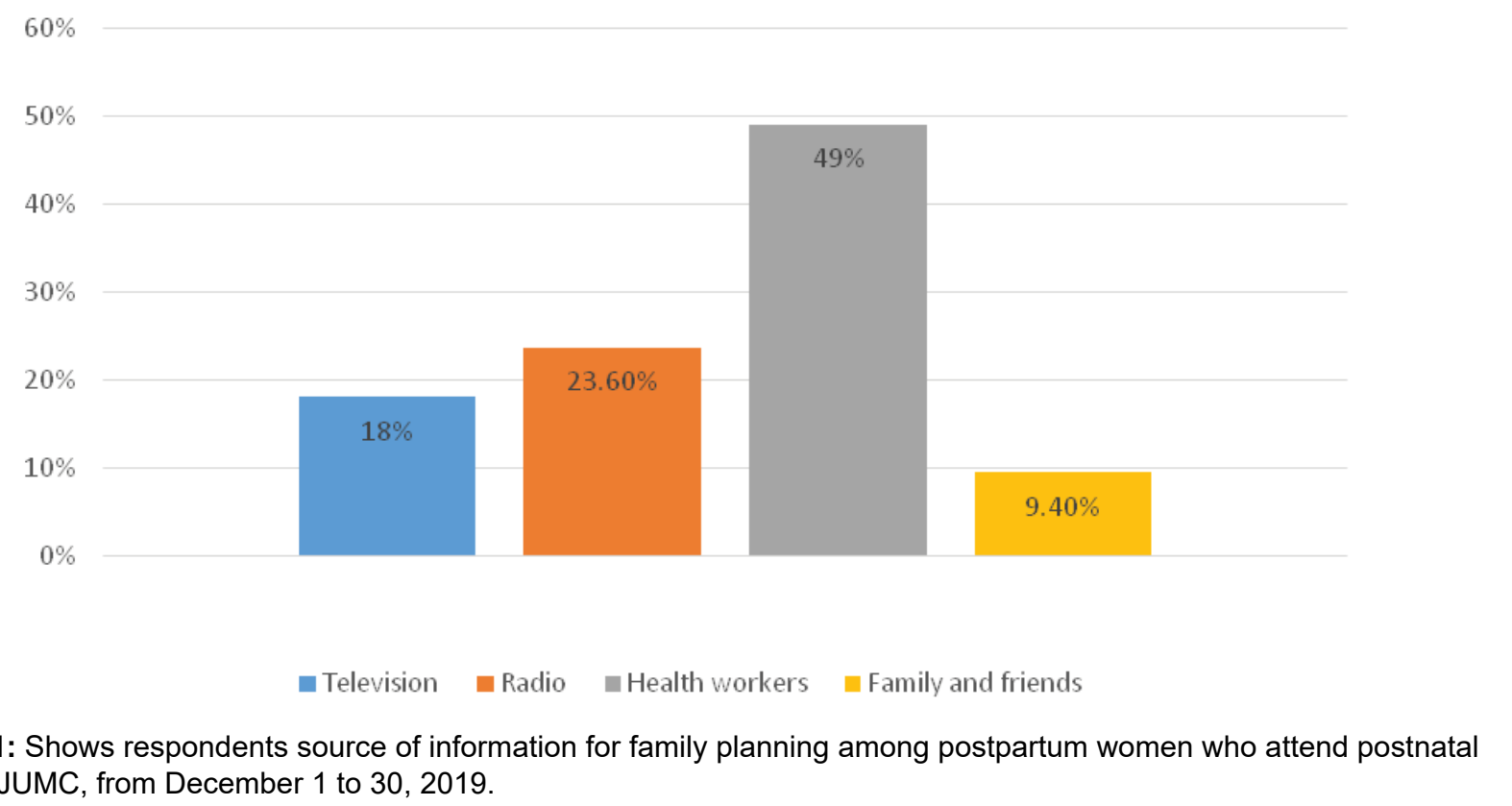

Figure 1: Shows respondents source of information for family planning among postpartum women who attend postnatal ward at JUMC, from December 1 to 30, 2019.

(30.1\%) couldn't read and write, 45 (43.5\%) complete primary school. Concerning occupational status of the women, the majority was house wife 58 (54.7\%). Regarding their marital status, Majority of them 92 (86.8\%) was married. In terms of religion $48(45.3 \%)$ were Muslims. As for monthly income 12 (11.3\%) got less than 1000 birr and 94 (88.7\%) get 1000 birr and above. With regard to reproductive history related to number of pregnancy showed that $12(11.3 \%)$ were one pregnancy they experience and $94(88.7 \%)$ were two and above pregnancy (Table 1 ).

\section{Knowledge of contraceptive use among postpartum mothers}

Only 98 (92.5\%) of the respondents had heard about family planning. About $65.7 \%$ have good knowledge, $34.3 \%$ have poor knowledge. Accordingly, the most known methods to the respondents were injectable
(85\%), and followed by pills (42.5\%). Among the sources of information for contraceptive $52(49 \%)$ were health workers (Figure 1).

Majority of respondents get access for family planning $45(42.5 \%)$ were from hospitals followed by $38(35.8 \%)$ were health center. Regarding to their current choose of contraceptive $45(42.5 \%)$ were choose injectable followed by 25 (23.6\%) were pills. Regarding to side effects of contraceptive majority of them $72(67.9 \%)$ were replied as it has side effects. Majority of respondents faced to side effects $20(27.8 \%)$ were irregular bleeding. Most of the respondents 90(84.9\%) were agree as IUD has no effects on infant breast feeding (Table 2).

\section{Attitude of postpartum mothers towards contraceptive use}

Out of 106 respondents, about two third 74(69.8\%) 
Table 2: Distribution of respondent's knowledge toward contraceptive use among postpartum women who attend postnatal ward at JUMC, from December 1 to 30, 2019.

\begin{tabular}{|c|c|c|c|}
\hline Variables & Categories & Frequency & Percentage \\
\hline \multirow{2}{*}{$\begin{array}{l}\text { 1. Have you ever heard of } \\
\text { birth contraceptive? }\end{array}$} & Yes & 98 & 92.5 \\
\hline & No & 8 & 7.5 \\
\hline \multirow{4}{*}{$\begin{array}{l}\text { 2. What is your source of } \\
\text { information for FP? }\end{array}$} & TV & 19 & 18 \\
\hline & Radio & 25 & 23.6 \\
\hline & Health workers & 52 & 49 \\
\hline & Family and friends & 10 & 9.4 \\
\hline \multirow{4}{*}{$\begin{array}{l}\text { 3. Where do you get access } \\
\text { for FP? }\end{array}$} & Hospitals & 45 & 42.5 \\
\hline & Health center & 38 & 35.8 \\
\hline & Health post & 14 & 13.2 \\
\hline & Private clinics & 9 & 8.5 \\
\hline \multirow{7}{*}{$\begin{array}{l}\text { 4. Can you mention the } \\
\text { method that you know? (More } \\
\text { than one answer is possible.) }\end{array}$} & Condoms & 40 & 37.7 \\
\hline & LAM & 30 & 28.3 \\
\hline & Pills & 45 & 42.5 \\
\hline & Injection & 90 & 85 \\
\hline & Implant & 25 & 23.6 \\
\hline & Intrauterine & 21 & 19.5 \\
\hline & Permanent method & 6 & 5.6 \\
\hline \multirow{6}{*}{$\begin{array}{l}\text { 5. What is your current choose } \\
\text { of contractive? }\end{array}$} & Condoms & 10 & 9.4 \\
\hline & LAM & 6 & 5.6 \\
\hline & Pills & 25 & 23.6 \\
\hline & Injection & 45 & 42.5 \\
\hline & Implant & 12 & 11.3 \\
\hline & Intrauterine & 8 & 7.5 \\
\hline \multirow{2}{*}{$\begin{array}{l}\text { 6. Do contraceptive have side } \\
\text { effect? }\end{array}$} & Yes & 72 & 67.9 \\
\hline & No & 34 & 32.1 \\
\hline \multirow{6}{*}{$\begin{array}{l}\text { 7. If "Yes" for } Q 6 \text { which of } \\
\text { the following side effects } \\
\text { experienced by you while } \\
\text { using the contraceptive }\end{array}$} & Nausea/Vomiting & 6 & 8.3 \\
\hline & Headaches & 7 & 9.7 \\
\hline & Irregular bleeding & 20 & 27.8 \\
\hline & $\begin{array}{l}\text { Heavy and prolonged } \\
\text { menstrual bleeding }\end{array}$ & 15 & 20.8 \\
\hline & Abdominal pain & 14 & 19.4 \\
\hline & Breast tenderness & 10 & 13.9 \\
\hline \multirow{2}{*}{$\begin{array}{l}\text { 8. IUD have no effect on infant } \\
\text { breast feeding? }\end{array}$} & Yes & 90 & 84.9 \\
\hline & No & 16 & 15.1 \\
\hline \multirow{2}{*}{$\begin{array}{l}\text { 9. Is it oral contraceptive } \\
\text { pills given for breast feeding } \\
\text { mother? }\end{array}$} & Yes & 85 & 80.2 \\
\hline & No & 21 & 19.8 \\
\hline \multirow{2}{*}{$\begin{array}{l}\text { 10. Are you familiar with } \\
\text { lactation amenorrhea method } \\
\text { of contraceptive? }\end{array}$} & Yes & 49 & 46.2 \\
\hline & No & 57 & 53.8 \\
\hline
\end{tabular}

were favorable (positive) attitude towards contractive. Less than three fourth of respondents $76(71.7 \%)$ were agreed to importance of partner discussion about family planning. More than four fifth $91(85.8 \%)$ were interest to know about family planning. About 98 (92.5\%) of respondents were replied as using family planning important for women and 73(68.9\%) were replied as important for the family. About 49(46.2\%) were replied as having many children is asset for the family and less than half of $50(47.2 \%)$ respondents were replied as family who had many sons is respected than family who had many female (Table 3).

Practice towards contraceptive use among postpartum mothers

Out of 106 respondents about more than half 
Table 3: Frequency distribution of attitudes of respondents towards contraceptive use among postpartum women who attend postnatal ward at JUMC, from December 1 to 30, 2019.

\begin{tabular}{|c|c|c|c|}
\hline Variables & Categories & Frequency & Percentage \\
\hline \multirow[t]{2}{*}{ 1. Partner discussion about FP is important? } & Agree & 76 & 71.7 \\
\hline & Disagree & 30 & 28.3 \\
\hline \multirow[t]{2}{*}{ 2. Do you have interest to know about FP? } & Agree & 91 & 85.8 \\
\hline & Disagree & 15 & 14.2 \\
\hline \multirow[t]{2}{*}{ 3. Using FP is important for women? } & Agree & 98 & 92.5 \\
\hline & Disagree & 8 & 7.5 \\
\hline \multirow[t]{2}{*}{ 4. Using FP is important for the family? } & Agree & 73 & 68.9 \\
\hline & Disagree & 33 & 31.1 \\
\hline \multirow[t]{2}{*}{ 5. Large family size affects development of a family? } & Agree & 62 & 58.5 \\
\hline & Disagree & 44 & 41.5 \\
\hline \multirow[t]{2}{*}{ 6. Do you have interest to use FP? } & Agree & 75 & 70.8 \\
\hline & Disagree & 31 & 29.2 \\
\hline \multirow[t]{2}{*}{ 7. Advising other women for FP is goodlappropriate? } & Agree & 81 & 76.4 \\
\hline & Disagree & 25 & 23.6 \\
\hline \multirow[t]{2}{*}{ 8. Having many children is an asset for the family? } & Agree & 49 & 46.2 \\
\hline & Disagree & 57 & 53.8 \\
\hline \multirow{2}{*}{$\begin{array}{l}\text { 9. Family who had many sons is respected than family } \\
\text { who had many female? }\end{array}$} & Agree & 50 & 47.2 \\
\hline & Disagree & 56 & 52.8 \\
\hline \multirow[t]{2}{*}{ 10. It isn't sin to use FP? } & Agree & 59 & 55.6 \\
\hline & Disagree & 47 & 44.4 \\
\hline
\end{tabular}

Table 4: Distribution of respondents practice towards contraceptive use among postpartum women who attend postnatal ward at JUMC, from December 1 to 30, 2019.

\begin{tabular}{|c|c|c|c|}
\hline Variables & Categories & Frequency & Percentage \\
\hline \multirow[t]{2}{*}{ 1. Have you ever used FP before? } & Yes & 68 & 64.2 \\
\hline & No & 38 & 35.8 \\
\hline \multirow[t]{2}{*}{ 2. Is your reason to use contraceptive is to improve your own and child health? } & Yes & 74 & 69.8 \\
\hline & No & 32 & 30.2 \\
\hline \multirow[t]{2}{*}{ 3. Is your reason to use contraceptive is Prevent unwanted pregnancy? } & Yes & 85 & 80.2 \\
\hline & No & 21 & 19.8 \\
\hline \multirow[t]{2}{*}{ 4. Is your reason to use contraceptive is socioeconomic reasons? } & Yes & 79 & 74.5 \\
\hline & No & 27 & 25.5 \\
\hline \multirow{2}{*}{$\begin{array}{l}\text { 5. Is your reason to use contraceptive is recommended by health } \\
\text { professionals? }\end{array}$} & Yes & 23 & 21.7 \\
\hline & No & 83 & 78.3 \\
\hline \multirow[t]{2}{*}{ 6. Do you have other reason to use contraceptive? } & Yes & 8 & 7.5 \\
\hline & No & 98 & 92.5 \\
\hline \multirow{2}{*}{$\begin{array}{l}\text { 7. Do you choose one contraceptive from the other after you Counseled by } \\
\text { health professionals? }\end{array}$} & Yes & 89 & 84 \\
\hline & No & 17 & 16 \\
\hline \multirow{2}{*}{$\begin{array}{l}\text { 8. Do you choose one contraceptive from the other after Advertising on social } \\
\text { media? }\end{array}$} & Yes & 76 & 71.7 \\
\hline & No & 30 & 28.3 \\
\hline \multirow{2}{*}{$\begin{array}{l}\text { 9. Do you choose one contraceptive from the other after Health personal } \\
\text { chooses for you? }\end{array}$} & Yes & 19 & 17.9 \\
\hline & No & 87 & 82.1 \\
\hline \multirow{5}{*}{$\begin{array}{l}\text { 10. Contraceptive Method that you used in the past? More than one answer is } \\
\text { possible. }\end{array}$} & Pills & 58 & 54.7 \\
\hline & Injection & 104 & 98.1 \\
\hline & Implant & 25 & 23.6 \\
\hline & IUCD & 20 & 18.9 \\
\hline & Others & 12 & 11.3 \\
\hline
\end{tabular}




\begin{tabular}{|c|c|c|c|}
\hline \multirow[t]{2}{*}{ 11. Do you want to use contraceptive in the future? } & Yes & 89 & 84 \\
\hline & No & 17 & 16 \\
\hline \multirow[t]{6}{*}{$\begin{array}{l}\text { 12. What is the reason you do not want to use contraceptive? (can choose } \\
\text { more than one answer) }\end{array}$} & $\begin{array}{l}\text { Still want } \\
\text { to have a } \\
\text { children }\end{array}$ & 14 & 82.4 \\
\hline & $\begin{array}{l}\text { Lack of } \\
\text { information } \\
\text { of family } \\
\text { planning/ } \\
\text { contraceptive }\end{array}$ & 8 & 47.1 \\
\hline & $\begin{array}{l}\text { Fear of side } \\
\text { effects }\end{array}$ & 16 & 94.1 \\
\hline & $\begin{array}{l}\text { Prohibition of } \\
\text { parents/family }\end{array}$ & 6 & 35.3 \\
\hline & $\begin{array}{l}\text { Prohibition of } \\
\text { husbands }\end{array}$ & 9 & 53 \\
\hline & Others & 5 & 29.4 \\
\hline
\end{tabular}

\section{THE REASON OF RESPONDENTS NOT WILLING TO USE CONTRACEPTIVE IN THE FUTURE.}

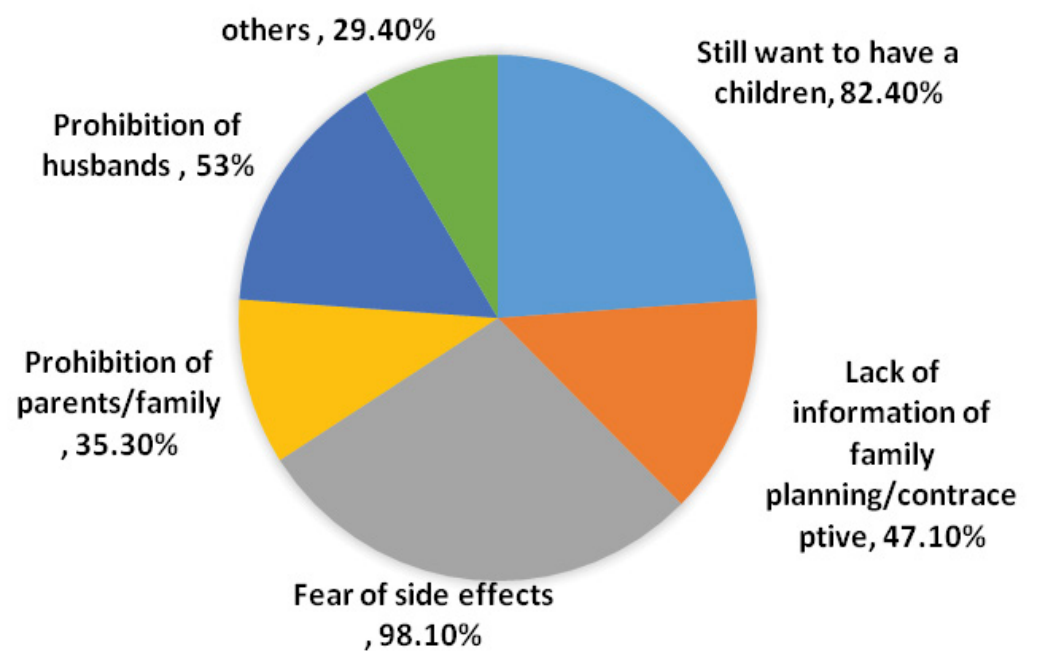

Figure 2: Shows the reason of respondents not willing to use contraceptive in the future among postpartum women who attend postnatal ward at JUMC, from December 1 to 30, 2019.

$62(58.5 \%)$ of respondents had a safe practice towards contraceptive use. About 68(64.2\%) of respondents were used family planning previously. The reason to use contraceptive as replied by respondents $74(69.8 \%)$ were to improve their own and child health, 85(80.2\%) were to prevent unwanted pregnancy, 79(74.5\%) were socioeconomic reason, $23(21.7 \%)$ were recommended by health professional. The respondents are choose one contraceptive from the others about 89(84\%) were after they counseled by health professionals. About 104(98.1\%) of respondents were used injectable contraceptive in the past followed by $58(54.7 \%)$ were used pills. Majority of the respondents $89(84 \%)$ were willing to use contraceptive in the future (Table 4).

They mentioned there reason not to use contraceptive in the future $16(94.1 \%)$ were fear of side effects, followed by $14(82.4 \%)$ were still want to have a children and $8(47.1 \%)$ were lack of information about family planning (Figure 2).

\section{Discussion}

This study assessed KAP of mothers towards postpartum family planning in JUMC, Ethiopia.

In this study about $65.7 \%$ have good knowledge, $34.3 \%$ have poor knowledge. This result relatively agree with a study conducted in Adama [24] shows that The overall knowledge $63.6 \%$ and $36.4 \%$ participants have good and poor knowledge about contraceptive, respectively. The similarity may due to that study participants in Jimma zone and Adama were relatively residing in large city/town and this may help them to have a better access for family planning.

This result was low when compared a study conducted in a Kebribeyah Town, Somali Region [25] 
shows that among the respondents of 343,234 (68.2\%) had good knowledge. Whereas, one hundred nine $(31.8 \%)$ of the respondents had poor knowledge on postpartum contraceptive. This discrepancy might be due to sociocultural difference, difference in health care setting and difference in sociodemographic.

This result was also low when compared with a study conducted in Hosanna town shows that regarding the overall knowledge on Postpartum FP, majority of respondents 355 (96.5\%) were knowledgeable. Those discrepancies may be due to difference awareness towards contraceptive methods, difference in sample size, study setting and difference status of Jimma city/ town when compared with Hossaina.

In this study about 74(69.8\%) were positive attitude towards contractive and the remaining $32(30.2 \%)$ had negative attitude. This study finding was agree with study conducted in Nigeria shows that Up to 114(33.8\%) had a negative attitude towards FP. This result was high when compared with a study conducted in Adama [24] shows that accordingly more than half of (56.4\%) of the respondents have positive attitude and support use of contraceptives and $43.6 \%$ of them ad negative attitude for contraceptive use. And also it is high when compared with a study conducted in Kebribeyah Town, Somali Region shows that among the respondents, 278 (51\%) had favorable attitude toward postpartum contraceptive [25]. Those differences may be due to socio cultural difference, variation in the characteristics of the study population.

In this study Out of 106 respondents about more than half $62(58.5 \%)$ of respondents had a safe practice towards contraceptive use. This was high when compared with a study conducted in northwest Ethiopia shows that [26] almost half (50.4\%) of study participants had good practice and the rest $49.6 \%$ had poor practice. This result was high when compared with a study conducted in study conducted in Uttar Pradesh India Shows that [27] contraceptive practice in this study was $51.71 \%$ safe practice. And also it is high when compared with a study conducted in conducted in Pakistan shows that Of 100 interviewed women, 53 (53\%) had safe practice regarding to contraceptive methods. And also it is high when compared with a study conducted in Mahasamund district in Chhattishgarh State, India shows that about 78 (48.44\%) members had safe practice towards contraceptive use while $83(51.55 \%)$ members had unsafe practiced. Those differences may be due difference sociodemographic characteristics, difference in sample size and study area setting.

\section{Strength of the Study}

The study had $100 \%$ respondent rate.

It focuses on the KAP of post-partum family planning.

\section{Conclusion}

Nearly two third of respondents were knowledgeable and more than four fifth of respondents mostly know injectable contraceptive rather than others. More than two third of respondents were positive attitude towards contractive. About more than half of respondents had a safe practice.

\section{Recommendation}

Based on the finding of this study we would like to recommend:

The Jimma University Medical Center staff should teach ANC Attendant about importance of post-partum family planning to increase their knowledge, attitude and practice towards family planning.

The health extension worker and other concerned body should give health education about the importance of post-partum family planning for the baby and its effect for the mothers, more attention in rural area.

The majority of women relies heavily on short-acting methods, especially on injectable demonstrating the need for increased access to long-acting and permanent methods of FP, which are highly effective methods for women to achieve their desired pregnancy spacing/limiting needs.

\section{Competing Interests}

There is no competing interest.

\section{Authors' Contributions}

DB involved in designing of the study, data collection, data analysis, drafting and critically reviewing the manuscript. Likewise, TW commented in designing of the study, analysis of the data, develop and critically reviewing the manuscript. All authors read and approved the final manuscript.

\section{Consent for Publication}

Consent for publication is not applicable since there are no details, images, or videos relating to an individual person in this study.

\section{Funding}

This study was supported by Jimma University in partial fulfillment of the requirement for Bachelor of Science degree in nursing.

\section{Author Details}

Tilahun Wodaynew is lecturer of maternal health nursing in Jimma University, Dinkinesh Bekele is a professional nurse in Jimma University medical center.

\section{Acknowledgment}

My sincere and deepest gratitude goes to my 
advisors to Mr. Tilahun Wodaynew for his timely and constructive comments. I would like to thank Jimma University for official support and for free internet access for searching different literatures to prepare the thesis. My special thanks also goes to data collectors and supervisors who sacrified their valuable time to gather all the necessary information and support during the study period.

\section{References}

1. United Nations (2015) World Population Prospects: The 2015 Revision, Key Findings and Advance Tables. Department of Economic and Social Affairs, Population Division, New York, 1-8.

2. Ayele W, Tesfaye H, Gebreyes R, Gebreselassie AT (2013) Trends and determinants of unmet need for family planning and Programme options, Ethiopia. Further analysis of the 2000, 2005 and 2011 demographic and health surveys. DHS further analysis reports, Reports no 81, ICF International, Calverton.

3. Kassebaum JN, Bertozzi-Villa A, Coggeshall S, Shackelford KA, Steiner C, et al. (2014) Global, regional, and national levels and causes of maternal mortality during 1990-2013: A systematic analysis for the Global Burden of Disease Study 2013. Lancet 384: 980-1004.

4. Conde-Agudelo A, Belizán JM (2000) Maternal morbidity and mortality associated with interpregnancy interval. BMJ 321: 1255.

5. Subhi R, Ahmed H, Mawlood Z (2011) Spacing effects on maternal-child health. Tikrit Med J 17: 1-6.

6. (2015) Mariland family planning \& reproductive health program clinical guidelines.

7. (2012) Postpartum Evaluation and Contraception.

8. World Health Organization (2013) Programming strategies for postpartum family planning.

9. Shrah LB (2007) Family planning advice and postpartum contraceptive use among low-income women in Mexico. International Family Planning Perspectives 33: 6-12.

10. World Health Organization (2010) Report of a WHO technica consultation on birth spacing: Geneva, Switzerland 13-15 June 2005. WHO report, Geneva.

11. United Nations, Department of Economic and Social Affairs, Population Division (2015) Trends in Contraceptive Use Worldwide.

12. Ghana Statistical Service (GSS), Ghana Health Service (GHS), ICF Macro (2009) Ghana Demographic and Health Survey 2008.

13. (2012) A decade of change in contraceptive use in Ethiopia in-depth analysis of the EDHS 2000-2011.

14. Ethiopian Public Health Institute (EPHI), ICF (2019) Ethiopia Mini Demographic and Health Survey 2019: Key Indicators. Rockville, Maryland, USA.
15. MacPhail C, Pettifor A, Pascoe S, Rees H (2010) Contraceptive use and pregnancy among post-partum South African women: nationally representative crosssectional survey.

16. (2012) Determinants of contraceptive usage: Lessons from women in Osun State, Nigeria. Journal of Humanities and Social Science 1: 66-67.

17. Tamire M, Chalaand F, Lola M (2007) Knowledge, attitude and practice of family planning among high school students in North Gondar. Ethiopian Medical Journal 33: 21-22.

18. Thapa S, Rani A, Mishra CP (2014) Knowledge, attitude and belief about contraception in post-partum and post abortal women in a tertiary care Centre. Int $\mathrm{J}$ Reprod Contracept Obstet Gynecol 3: 533-539.

19. Bajracharya A (2015) Knowledge, attitude and practice of contraception among postpartum women attending Kathmandu Medical College Teaching Hospital. Kathmandu Univ Med J (KUMJ) 13: 292-297.

20. Sharma J, Dorairajan G, Chinnakali P (2015) Knowledge and attitude towards contraceptive methods for spacing and decision making factors regarding its use in postpartum women. IJRCOG.

21. Nath J, Islam F (2015) A study on the knowledge, attitude and practice about contraception in postpartum women of North India. IJSR 4.

22. (2017) Prevalence and associated factor toward postpartum modern contraceptive use in Axum, northern part of Ethiopia.

23. CSA, ICF International (2016) Ethiopia demographic and health survey 2016. CSA, ICF International, Addis Ababa and Rockville.

24. Abraham Z (2016) Intention to use contraceptive and determinants among postpartum women in health centers of Adama, Ethiopia.

25. Nigussie AT, Girma D, Tura G (2016) Postpartum Family Planning Utilization and Associated Factors among Women who Gave Birth in the Past 12 Months, Kebribeyah Town, Somali Region, Eastern Ethiopia. J Women's Health Care 5: 340 .

26. Kasa AS, Tarekegn M, Embiale N (2018) Knowledge, attitude and practice towards family planning among reproductive age women in a resource limited settings of Northwest Ethiopia. BMC Res Notes 11: 577.

27. Srivastav A, Khan MS, Chauhan CR (2014) Knowledge, Attitude and Practices about Contraceptive among Married Reproductive Females. International Journal of Scientific Study 1: 2-4.

28. Quereishi MJ, Mathew AK, Sinha A (2017) Knowledge, attitude and practice of family planning methods among the rural females of Bagbahara block Mahasamund district in Chhattishgarh State, India, 6: 1-7. 